\title{
Limiting Factors on Speed and Load of Diesel Engines Vehicle Urban Air Quality Management in Thailand
}

\author{
Kritchai Kongkratoke ${ }^{1}$, Surat Bualert ${ }^{1} \&$ Kasem Chunkao ${ }^{1,2}$ \\ ${ }^{1}$ Department of Environmental Science, Faculty of Environment, Kasetsart University, Bangkok, Thailand \\ ${ }^{2}$ The King's Royally Initiated Laem Phak Bia Environmental Research and Development Project, Chaipattana \\ Foundation \\ Correspondence: Kritchai Kongkratoke, Department of Environmental Science, Faculty of Environment, Kasetsart \\ University, Bangkok 10900, Thailand. E-mail: chinwatkong@gmail.com
}

Received: June 26, 2015

Accepted: September 2, 2015

Online Published: November 30, 2015

doi:10.5539/mas.v9n13p98

URL: http://dx.doi.org/10.5539/mas.v9n13p98

\begin{abstract}
Speed and load of diesel engine vehicles are the important factors affected on the fine particulate matter emission in Thailand. This study aimed to study the relation of speed and load of diesel engine vehicles affected on the emission of fine particulate matter in Thailand and also related to the emission of the exhaust from diesel engine vehicles. The experiment was designed into a x b Factorial Experiment in Completely Randomized Design. It was divided into 2 experiments as follows: 1) to study the emission of fine particulate matter in Euro 4 diesel engine vehicles, and 2) to study the emission of fine particulate matter in Euro 3 diesel engine vehicles. Moreover, it was to study 3 levels of speed in the driving form of diesel engine vehicles under Bangkok Driving Cycle, 3 levels of load, and 3 replications by using the experiment in Chassis Dynamometer System, and demonstrating the driving similarly to the actual driving. The samples of fine particulate matter from the exhaust were from the speed and load by using Micro-Orifice Uniform Deposition Impactors; MOUDI which had the size from 0.056-18 microns with the flow rate at 30 liter/ minute. The result from this study was found that the experiment of Euro 4 diesel engine vehicles had the factors of speed and load which affected on the emission of fine particulate matter at the level of 0.05 , and F-value was 240.03 and 4.60 respectively. About the experiment of Euro 4 diesel engine vehicles, it had the factors of speed and load which affected on the emission of fine particulate matter at the level of 0.05 , and F- value was 796.92 and 18.46 respectively. At the speed of $7.8 \mathrm{~km} / \mathrm{hr}$, the loads of empty vehicle and $1,000 \mathrm{~kg}$ of Euro 3 diesel engine vehicles were different at the level of 0.05 . While the speed of $7.8 \mathrm{~km} / \mathrm{hr}$ was at empty vehicle and 1,000 kg of Euro 4 diesel engine vehicles, it was not different in statistical significance. Therefore, there should be the regulations to control the load of the Euro 4 diesel engine vehicles lower than standard in the city with high traffic jam.
\end{abstract}

Keyword: diesel engine vehicle, speed, load and fine particulate matter

\section{Introduction}

Nowadays most of cities in the world are facing with air pollutant problem continuously. Importantly, this problem tends to be more and more serious. One of important causes is from the pollutants from the vehicles which are increasing rapidly (Duangmal et al., 2014) Moreover, using Fossil Fuel mostly which is important energy resource with the component of hydrocarbon or $\mathrm{HC}$ as the majority leads to many kinds of pollutants; and effects on people's health and sanitation directly. The pollutant that leads to the main problem in the area of urban is fine particulate matter. Pollution Control Department reported that the fine particulate matter is the smallest air pollutant which is more serious problem that others; especially in the area of big cities, they are also caused by pollutant resource from the vehicles with compression-ignition or diesel engine. The increasing number of vehicles and traffic in the big cities causes the problem of fine particulate matter intensely; especially Bangkok is found that it is the area having the problem of particulate matter all time. According to the survey from Air pointer of Pollution Control Department around the roadside and general area, it is found that the particulate matter with the size not more than 10 microns $\left(\mathrm{PM}_{10}\right)$ in the roadside, average of 24 hours is checked at the range of $7.4-131.5$ micrograms/ cubic meter. The results from checking the quality of the air around roadside are found that there are the times with over standard more than other air pollutants, and the times with over standard are calculated to much more proportion than other general areas. 
However, the problem of particulate matter not more than 10 microns $\left(\mathrm{PM}_{10}\right)$ is fully found in the area of big cities; especially around the roadside with high traffic jam, there is the smaller 10 microns fine particulate matter which is able to be suspended in the air. The results from the relation between the particulate not more than 25 microns $\left(\mathrm{PM}_{2.5}\right)$ in the atmosphere affected on the population's health; for example, premature death, sickness of respiratory diseases, symptoms of respiratory system. Because, the particulate matter not more than 2.5 microns $\left(\mathrm{PM}_{2.5}\right)$ tends to spread into lower respiratory system, and be the residue longer than the bigger particulate matter (Khan et al., 2010). The study related to the epidemiology in Thailand recently, it is found that the effect of particulate matter not more than 2.5 microns $\left(\mathrm{PM}_{2.5}\right)$ on the health and sanitation is similar level to the study of areas around urbans of the world.

Although, Thailand has the regulations related to the standard of particulate matter in the atmosphere, it is found that the standard setting above is focused on 2 sizes of particulate matter consisted of particulate matter not more than 10 microns $\left(\mathrm{PM}_{10}\right)$ and not more than 2.5 microns $\left(\mathrm{PM}_{2.5}\right)$. The previous study was found that the important origin was from the vehicles especially compression-ignition engine by using diesel fuel; including the factors of speed and load. Therefore, this study aims to study the relation of speed and load of diesel engine vehicles to the emission of fine particulate matter which is beneficial to the problem management of air pollutants caused by the vehicles in the urban area. Finally, it will lead to the policy or regulation of air pollutant control in Thailand accordingly.

\section{Material and Methods}

\subsection{Material}

1) The instruments of Chassis dynamometer system are used for the test of pollutants emission regarding the vehicles weight by creating the speed drag of the test. The test of diesel engine vehicles consisted of the important instruments as follows:

1.1) Chassis dynamometer is the instrument in mechanical unit consisted of the single roller that can recover the mechanical loss automatically.

1.2) Cooling fan is used for creating the wind as same as driving on the road for heat extracting of the engine system from engine working. It will be work corporately with chassis dynamometer which is able to the speed of wind around the vehicle as same as the actual vehicles on the road as per the driving cycle.

1.3) Control unit is the set for controlling the work of chassis dynamometer and cooling fan. It can be set the condition of resistance in the test and working control of the instrument regarding the standard of regulations and the condition of test; including recordable to the relation of speed and time in the test for assessing the correctness of the test form.

2) Exhaust gas sampling system is used for collecting the samples of pollutants from vehicles' exhaust pipe by air diluting with Critical Flow Venture (CFV) to control the flowing rate of stable mixture samples, then it will be sent to the bag of collecting samples for checking the pollutants. Sampling unit is used for diluting the exhaust with the air continuously until it is mixed. There are the instruments for eradicating the dust and humidity; including the instruments used for measuring the volume of mixed air samples. The mixture suction set is used for controlling the flow rate of the mixed samples continuously and stably (Nilrit et al., 2013)

3) Micro-Orifice Uniform Deposition Impactors; MOUDI is used for collecting the samples of fine particulate matter. The filter set has a big amount of small hole, 10 filter layers, and sizing from 0.056- 18 microns as shown in the Table 1 which is to study the distribution of fine particulate matter. From this, it can select the size of fine particulate matter for finding the amount of fine particulate matter in the terms of weight; including is able to find the component in the samples. Micro-Orifice Uniform Deposition Impactors; MOUDI has the flow rate at 30 liter/ minute.

4) Filter paper of Fine particulate matter; PM is the filter paper for sampling the matter. Before sampling, it will be dried and temperature controlled at 20-30 Degree Celsius. There is the absolute humidity of the air in the test room between 5.5- $12.2 \mathrm{~g}$ of $1 \mathrm{~kg}$ of steam in the dried air for 8 hours. Then, it will be weighed for collecting the sampling. After that, the filter paper used for testing the sample vehicles will be also weighed.

5) Multichannel recorder is used for recording the pollutants measured from the pollutants analysis machine for processing the correctness of the test.

6) Inclined - tube manometer is used for pressure measuring within the Crankcase for the engine with the deviation not more than $\pm 0.01 \mathrm{KPa}$. 
7) U-Tube thermometer is used for temperature measuring which has the failures not more than \pm 1.0 Degree Celsius.

8) The precision forting barometer is used for air pressure measuring in the test room which has the fineness at \pm $0.01 \mathrm{KPa}$ as shown on the computer with automatically processing ability.

9) Precision hair hygrothermometer is used for absolute humidity measuring in the test room with the fineness at $\pm 5 \%$, and has the sensor for checking the absolute humidity in the test room with the fineness at $\pm 5 \%$ as shown on the computer with automatically processing ability.

10) Vehicle weighing apparatus is used for weighing the vehicle in the test for the real weight. Before moving the vehicle on Chassis dynamometer, the sampling vehicle will be weighed for getting the real and correct weight.

Table 1. The sieve analysis of fine particulate matter by using Micro-Orifice Uniform Deposition Impactors; MOUDI

\begin{tabular}{ccc}
\hline Stage & Cut Size $(\mu \mathrm{m})$ & Number of Nozzles \\
\hline Inlet & 18 & 1 \\
1 & 10 & 1 \\
2 & 5.6 & 10 \\
3 & 3.2 & 10 \\
4 & 1.8 & 20 \\
5 & 1.0 & 40 \\
6 & 0.56 & 80 \\
7 & 0.32 & 900 \\
8 & 0.18 & 900 \\
9 & 0.10 & 2000 \\
10 & 0.056 & 2000 \\
Filter & 0 & - \\
\hline
\end{tabular}

\subsection{Methods}

This study uses the Factorial Experiment from treatment combination of related factors. This study aims to study about limiting factors on speed and load of diesel engines vehicle urban air quality management.

\section{1) Speed}

Speed (a) is the first independent variables. In this study, the vehicles were divided into 3 speed levels regarding the traffic condition covering the vehicles in Thailand as follows: 1) Average speed rate of vehicle movement in the provinces with the high traffic jam 2) Average speed rate of vehicle movement in the provinces with the medium traffic jam, and 3) Average speed rate of vehicle movement in the provinces with the low traffic jam. Therefore, three speed levels are related to Bangkok Driving Cycle. The speed levels of this study were divided into 3 levels consisted of a1 level $(7.8 \mathrm{~km} / \mathrm{hr})$, a2 level $(46.8 \mathrm{~km} / \mathrm{hr})$, and a3 level $(72.6 \mathrm{~km} / \mathrm{hr})$ respectively as shown in the Table 2.

2) Load

The load (b) is the second independent variables. In this study, chassis dynamometer system is able to support the total of vehicle weight and load not more than $3,500 \mathrm{~kg}$. Thus, this study divided the load into 3 levels: the loads of b1 (0 kg), b2 (500 kg), and b3 (1,000 kg) respectively.

Table 2. Bangkok Driving Cycle and diesel engines vehicle

\begin{tabular}{cccc}
\hline $\begin{array}{c}\text { LDDV } \\
\text { (LDT cycle) }\end{array}$ & Speed range $(\mathrm{km} / \mathrm{hr})$ & $\begin{array}{c}\text { Average speed } \\
(\mathrm{km} / \mathrm{hr})\end{array}$ & $\begin{array}{c}\text { Total time } \\
\text { (second) }\end{array}$ \\
\hline L1 & $0-10$ & 7.8 & 1063 \\
L2 & $10-20$ & 14.6 & 823 \\
L3 & $20-30$ & 23.1 & 601 \\
L4 & $30-40$ & 33.9 & 706 \\
L5 & $40-60$ & 46.8 & 730 \\
L6 & $60-90$ & 72.6 & 724 \\
\hline
\end{tabular}




\section{3) Samples}

This study was to study the emission of fine particulate matter from the exhaust of diesel engine vehicle application as the representatives of vehicles in Thailand. The study was divided into 2 experiments as follows: 1) Euro 4 diesel engine vehicles and 2) Euro 3 diesel engine vehicles. Therefore, this study has the experimental design into a x b Factorial Experiment with Completely Randomized Design. The study of speed rates of Light Duty Diesel Vehicle; LDDV were divided into 3 levels, and3 levels of load at $3 \times 3$ factorial, 9 treatments, 3 replications of 27 experimental units; including each unit has 10 levels. Thus, there were total 270 experimental units. This study also had 2 experiments for comparing the emission rates of fine particulate matter from collecting samplings with 10 sizes of Micro-Orifice Uniform Deposition Impactors; MOUDI between the diesel engine with the development of Euro 4 vehicles and vehicles with lower standard than Euro 4 as per the samples of experiment.

\begin{tabular}{|l|c|c|c|}
\hline \multirow{2}{*}{ Treatment } & \multicolumn{3}{|c|}{ Replication } \\
\cline { 2 - 4 } & & 1 & \\
\hline $\mathrm{T} 1: \mathrm{a} 1 \mathrm{~b} 1$ & & & \\
\hline $\mathrm{T} 2: \mathrm{a} 1 \mathrm{~b} 2$ & & & \\
\hline $\mathrm{T} 3: \mathrm{a} 1 \mathrm{~b} 3$ & & & \\
\hline $\mathrm{T} 4: \mathrm{a} 2 \mathrm{~b} 1$ & & & \\
\hline $\mathrm{T} 5: \mathrm{a} 2 \mathrm{~b} 2$ & & & \\
\hline $\mathrm{T} 6: \mathrm{a} 2 \mathrm{~b} 3$ & & & \\
\hline $\mathrm{T} 7: \mathrm{a} 3 \mathrm{~b} 1$ & & & \\
\hline $\mathrm{T} 8: \mathrm{a} 3 \mathrm{~b} 2$ & & & \\
\hline $\mathrm{T} 9: \mathrm{a} 3 \mathrm{~b} 3$ & & & \\
\hline
\end{tabular}

Figure 1. The chart of experiment

Statistical Hypothesis

1) Main effect $A$

$\mathrm{H}_{0}: \mu_{\mathrm{a} 1}=\mu_{\mathrm{a} 2}=\mu_{\mathrm{a} 3}$

$\mathrm{H}_{1}: \mu_{\mathrm{a} 1} \neq \mu_{\mathrm{a} 2} \neq \mu_{\mathrm{a} 3}$

When $\mu_{\mathrm{a} 1} \mu_{\mathrm{a} 2}$ and $\mu_{\mathrm{a} 3}$ are the mean of emission level and fine particulate matter distribution with the factors of 3level speed

2) Main effect $B$

$$
\begin{aligned}
& \mathrm{H}_{0}: \mu_{\mathrm{b} 1}=\mu_{\mathrm{b} 2}=\mu_{\mathrm{b} 3} \\
& \mathrm{H}_{1}: \mu_{\mathrm{b} 1} \neq \mu_{\mathrm{b} 2} \neq \mu_{\mathrm{b} 3}
\end{aligned}
$$

When $\mu_{\mathrm{b} 1} \mu_{\mathrm{b} 2}$ and $\mu_{\mathrm{b} 3}$ are the mean of emission level and fine particulate matter distribution with the factors of 3level pay load

3) AB Interaction

$$
\mathrm{H}_{0}: \mu_{\mathrm{a} 1 \mathrm{~b} 1}=\mu_{\mathrm{a} 1 \mathrm{~b} 2}=\mu_{\mathrm{a} 1 \mathrm{~b} 3}, \ldots, \mu_{\mathrm{anbn}}
$$


$\mathrm{H}_{1}$ : to have at least a pair of $\mu$ that is different

When $\mu_{\mathrm{a} 1 \mathrm{~b} 1}, \mu_{\mathrm{a} 1 \mathrm{~b} 2}, \mu_{\mathrm{a} 1 \mathrm{~b} 3}, \ldots$, are the mean of emission level and fine particulate matter distribution with the interacted factors of speed and pay load

There are 2 factors in the experiment with the characteristic of a x b factorial in Completely Randomized Design, and the repeating number is $r$ which has the statistical model as follows:

$$
\mathrm{Y}_{\mathrm{ijk}}=\mu+\alpha_{\mathrm{i}}+\beta_{\mathrm{j}}+\alpha \beta \mathrm{ij}+\mathrm{e}_{\mathrm{ijk}}
$$

When

$$
\begin{array}{ll}
\mathrm{I} & =1,2, \ldots, \mathrm{a} \\
\mathrm{J} & =1,2, \ldots, \mathrm{b} \\
\mathrm{K} & =1,2, \ldots, \mathrm{r}
\end{array}
$$

$\mathrm{Y}_{\mathrm{ijk}}=$ Treatment combination observation value of I level of factor A, j level of factor B, and experimental unit $\mathrm{k}$

$$
\begin{aligned}
& \mu=\text { Total mean } \\
& \alpha_{\mathrm{i}}=\text { The influence of factor } \mathrm{A} \\
& \beta_{\mathrm{j}}=\text { The influence of factor } \mathrm{B} \\
& \alpha \beta_{\mathrm{ij}}=\text { The influence of interacted factor AB } \\
& \mathrm{e}_{\mathrm{ijk}}=\text { The deviation of experiment }
\end{aligned}
$$

When taking the result from experiment for Analysis of Variance, the factorial experiment with 2 factors in Completely Randomized Design after Analysis of Variance will have the difference between the treatment mean.

\section{Results}

\subsection{Experimental Results of Euro 4 Vehicles}

1) Two-Way Analysis of Variance in the experiment of Euro 4 vehicles was found that the factor of speed and pay load were affected on the emission of fine particulate matter at the level of 0.05 , F- Values are 240.03 and 4.60 respectively as shown in the Figure 2 and Table 3 . The coefficient of determination by $\mathrm{R}^{2}$ between MOUDI (Micro-Orifice Uniform Deposition Impactors) and CVS (Constant Volume Sampler ;) $\mathrm{R}^{2}$ - Values are 0.817, 0.954 and 0.931 respectively as shown in the Figure 3.

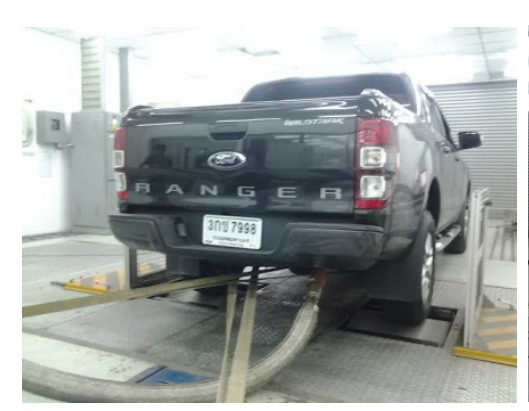

No. 1

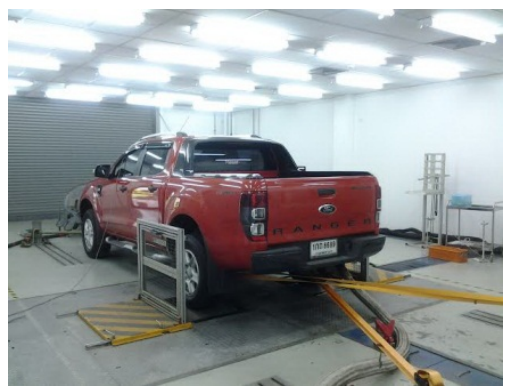

No. 2

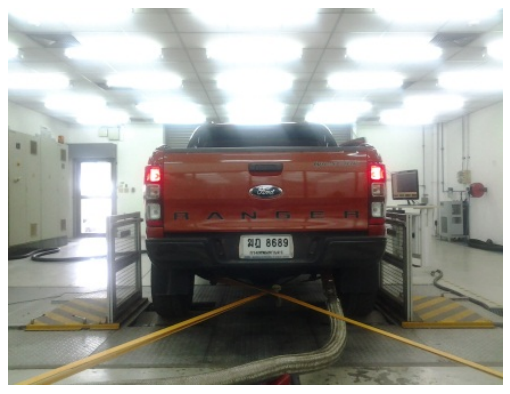

No.3

Figure 2. Euro 4 Light Duty Diesel Vehicles, LDDV in Thailand 

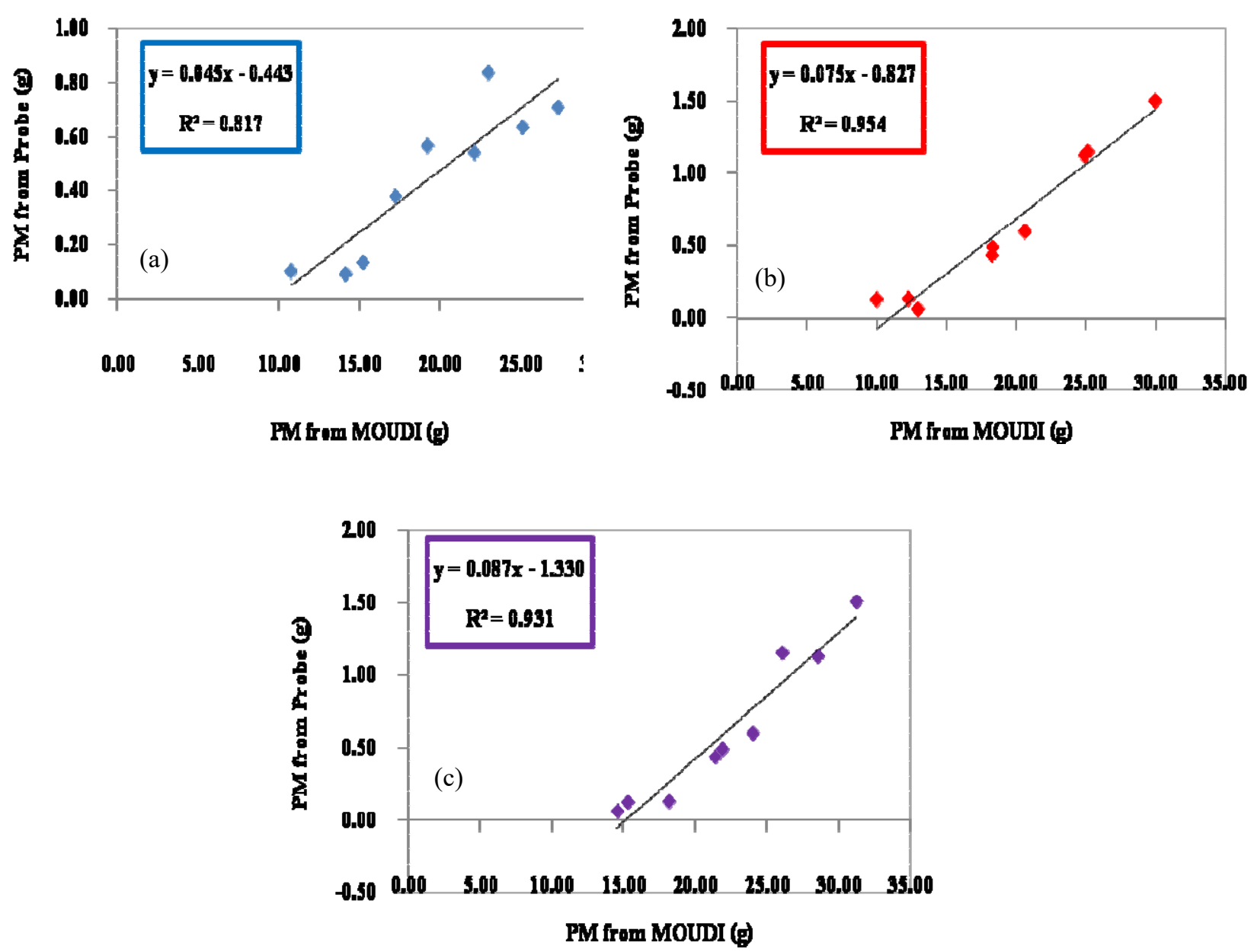

Figure 3. The coefficient of determination by $\mathrm{R}^{2}$ between MOUDI and CVS (a) No.1 (b) No.2 and (c) No3 Euro 4 vehicles

Table 3. Two-Way Analysis of Variance in the experiment of Euro 4 vehicles

\begin{tabular}{ccccccc}
\hline $\begin{array}{c}\text { Source of } \\
\text { Variation }\end{array}$ & SS & df & MS & F & P-value & F crit \\
\hline Sample & 9.5 & 2 & 4.75 & 240.03 & 7.17 & 3.03 \\
Columns & 0.18 & 2 & 0.09 & 4.6 & 0.01 & 3.03 \\
Interaction & 0.14 & 4 & 0.03 & 1.83 & 0.12 & 2.4 \\
Within & 5.16 & 261 & 0.01 & & & \\
Total & 14.99 & 269 & & & & \\
\hline
\end{tabular}

2) The results from t- test for finding the difference of speed and load on the emission of fine particulate matter from Euro 4 vehicles as follows:

\section{1) Speed of $7.8 \mathrm{~km} / \mathrm{hr}$}

The comparisons of $0 \mathrm{~kg}$ load and $500 \mathrm{~kg}$ load and $0 \mathrm{~kg}$ load and $1,000 \mathrm{~kg}$ load were not different. About $500 \mathrm{~kg}$ of load and 1,000 kg of load, they were different at the statistical significance of 0.05 , and t- value is 2.22 .

\section{2) Speed of $46.8 \mathrm{~km} / \mathrm{hr}$}

The comparisons of $0 \mathrm{~kg}$ load and $500 \mathrm{~kg}$ load and $0 \mathrm{~kg}$ load and $1,000 \mathrm{~kg}$ load were not different. About $500 \mathrm{~kg}$ of load and $1,000 \mathrm{~kg}$ of load, they were not different at the statistical significance of 0.05 . 
When $0 \mathrm{~kg}$ load and $500 \mathrm{~kg}$ load was compared with $500 \mathrm{~kg}$ load and 1,000 $\mathrm{kg}$ load, they were not different. About $0 \mathrm{~kg}$ load and 1,000 kg load, they were different at the level of 0.05 , and t-test was 2.65 .

According to the analysis of statistical variance, it was explained to the correlation of speed and load affected on the emission of fine particulate matter in Euro 4 diesel engine vehicles as shown in the Figure 4.

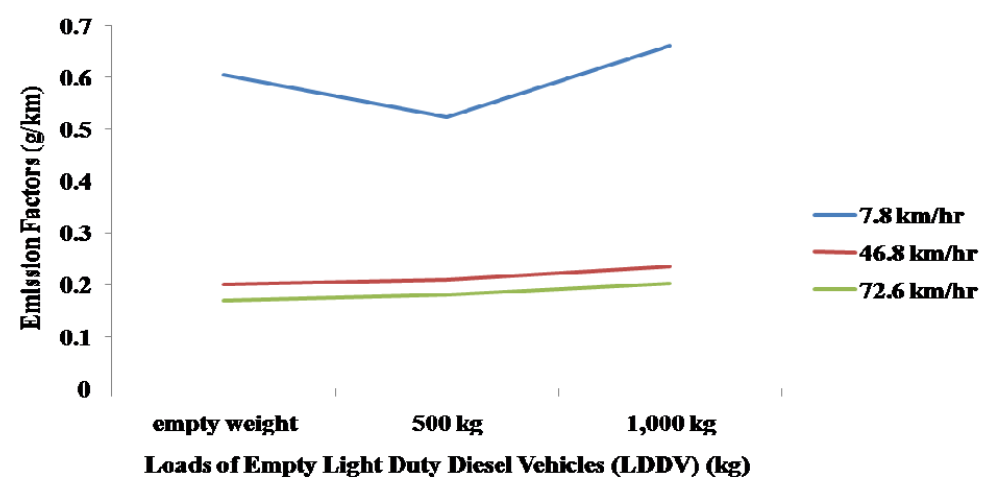

Figure 4. The correlation of speed and load affected on the emission of fine particulate matter in Euro 4 diesel engine vehicles

\subsection{The Experimental Results in Euro 3 Diesel Engine Vehicles}

1) The results from Two-Way Analysis of Variance in the experiment of Euro 3 diesel engine vehicles were found that the factors of speed and load affected on the emission of fine particulate matter at the level of 0.05 , and F- Value was 796.92 and 18.45 respectively. The interaction of the speed and load with F- Values was 10.26 as shown in the Figure 5 and Table 4 . The coefficient of determination by $\mathrm{R}^{2}$ between MOUDI (Micro-Orifice Uniform Deposition Impactors) and CVS (Constant Volume Sampler ;) $\mathrm{R}^{2}$ - Values are 0.75, 0.985 and 0.668 respectively as shown in the Figure 6.

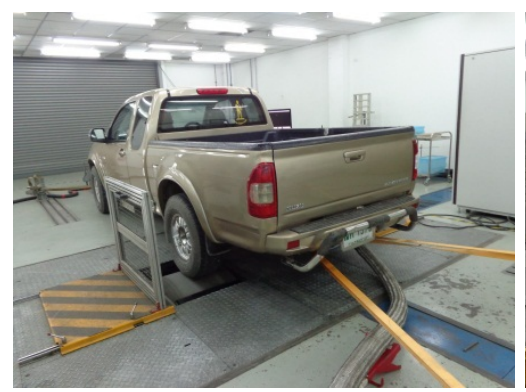

No.1

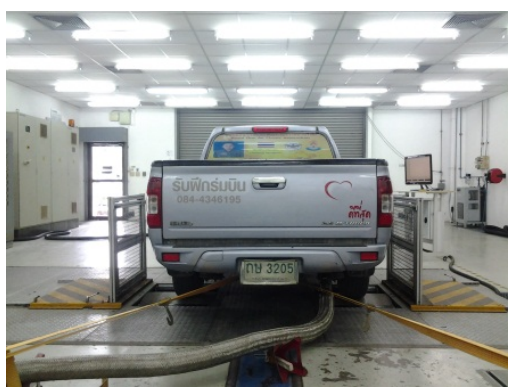

No.2

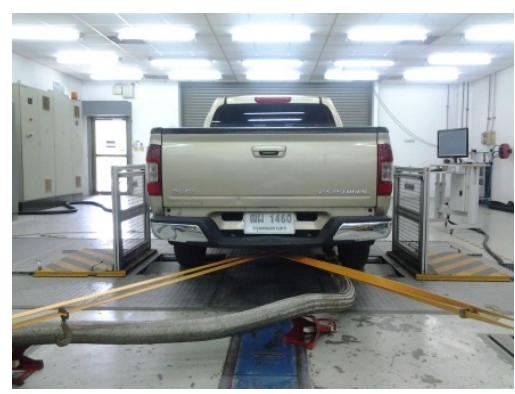

No.3

Figure5 . Euro 3 Light Duty Diesel Vehicles; LDDV in Thailand

Table 4. the results from Two-Way Analysis of Variance in the experiment of Euro 3 diesel engine vehicles

\begin{tabular}{ccccccc}
\hline $\begin{array}{c}\text { Source of } \\
\text { Variation }\end{array}$ & SS & df & MS & F & P-value & F crit \\
\hline Sample & 68.39 & 2 & 34.19 & 796.92 & 7.20 & 3.03 \\
Columns & 1.58 & 2 & 0.79 & 18.45 & 3.17 & 3.03 \\
Interaction & 1.76 & 4 & 0.44 & 10.26 & 9.87 & 2.40 \\
Within & 11.19 & 261 & 0.04 & & & \\
Total & 82.93 & 269 & & & & \\
\hline
\end{tabular}



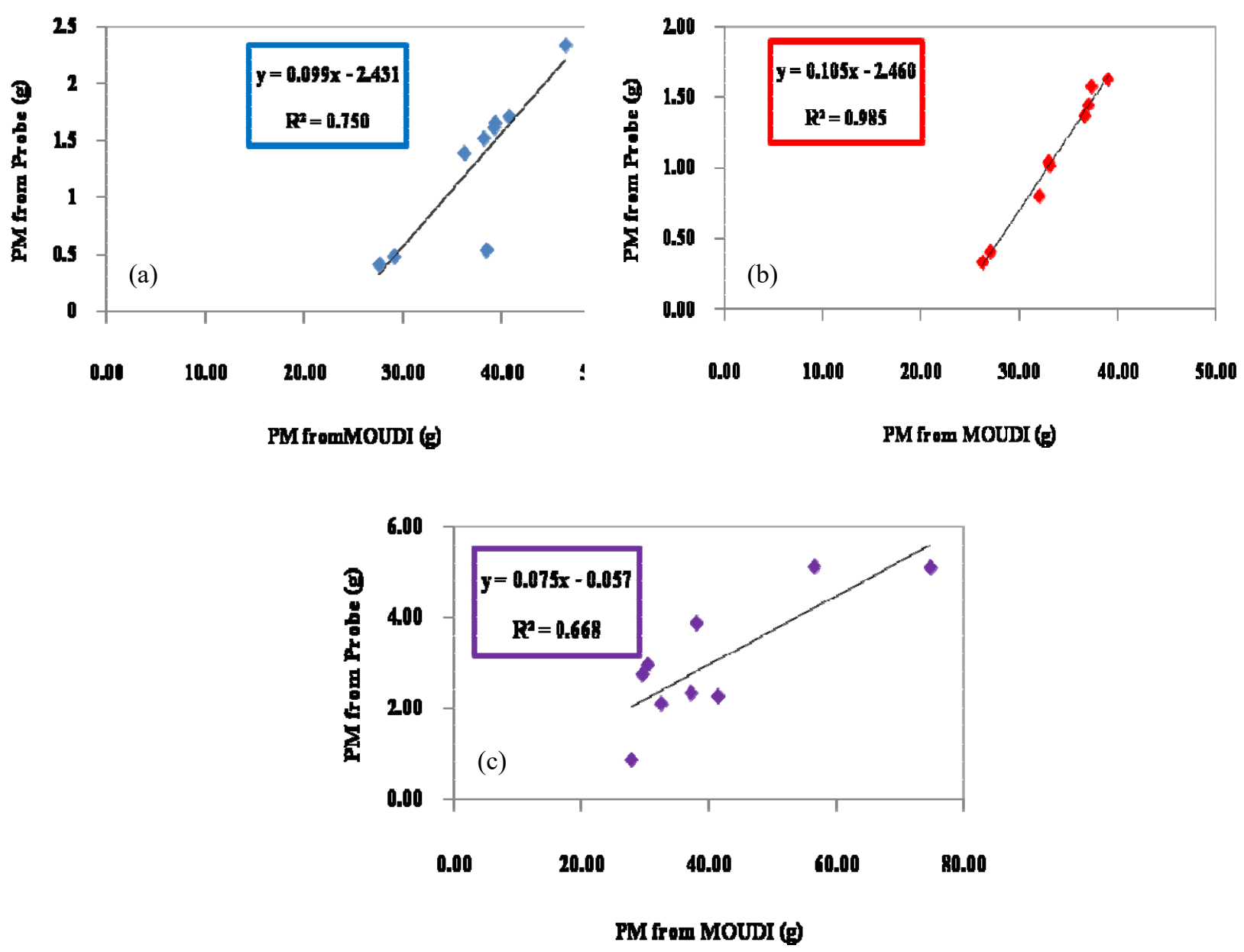

Figure 6. The coefficient of determination by $\mathrm{R}^{2}$ between MOUDI and CVS (a) No.1 (b) No.2 and (c) No.3 from Euro 4 vehicles

2) The results from t-test for finding the difference of speed and load on the emission of fine particulate matter from Euro 3 vehicles as follows:

2.1) Speed of $7.8 \mathrm{~km} / \mathrm{hr}$

The loads of $0 \mathrm{~kg}$ and $500 \mathrm{~kg}$ were not different. The comparisons of $0 \mathrm{~kg}$ load and 1,000 kg load and $500 \mathrm{~kg}$ load and $1,000 \mathrm{~kg}$ load were different at the level of 0.05 , t-test was 4.82 and 4.51 respectively.

2.2) Speed of $46.8 \mathrm{~km} / \mathrm{hr}$

The loads of $500 \mathrm{~kg}$ and $1,000 \mathrm{~kg}$ were not different. The comparisons of $0 \mathrm{~kg}$ load and $500 \mathrm{~kg}$ load and $0 \mathrm{~kg}$ load and $1,000 \mathrm{~kg}$ load were different at the level of 0.05 , t-test was 2.96 and 3.11 respectively.

2.3) Speed of $72.6 \mathrm{~km} / \mathrm{hr}$

The comparisons of $0 \mathrm{~kg}$ load and $500 \mathrm{~kg}$ load, $0 \mathrm{~kg}$ load and 1,000 kg load, and $500 \mathrm{~kg}$ load and 1,0 00kg load were not different at the level of 0.05 .

According to the analysis of statistical variance, it was explained to the correlation of speed and load affected on the emission of fine particulate matter in Euro 3 diesel engine vehicles as shown in the Figure 7. 


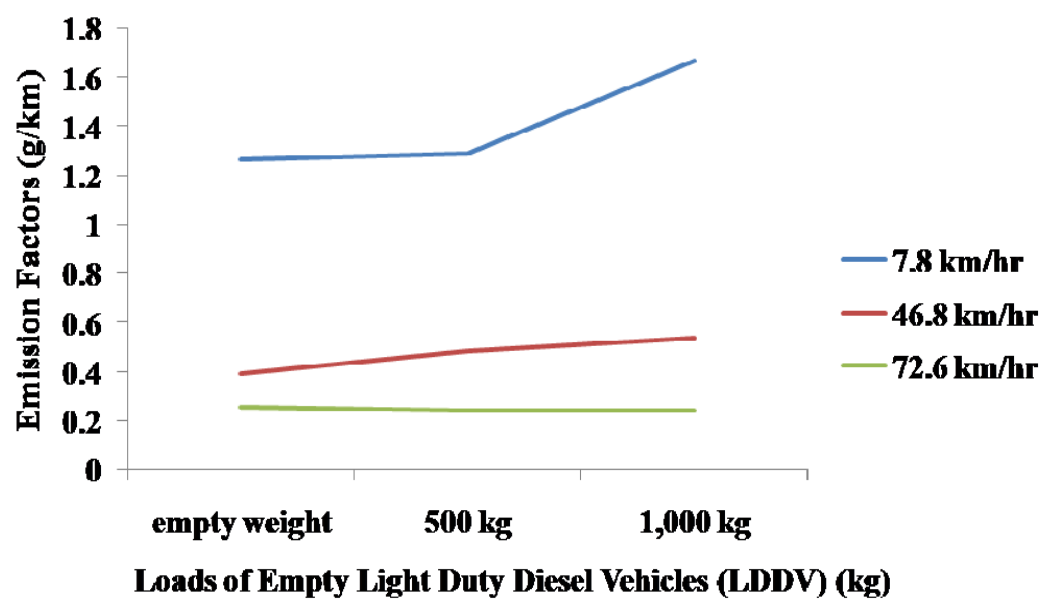

Figure 7. the correlation of speed and load affected on the emission of fine particulate matter in Euro 3 diesel engine vehicles

\section{Discussion}

These results correspond with Corsmeier et al. (2005) referenced a separate publication giving a full description of the measurement site and the vehicle counts. Given that each of the sites could be classified as "urban" (20 $\left.\mathrm{km} \mathrm{h}^{-1}\right)$, "rural" $\left(60 \mathrm{~km} \mathrm{~h}^{-1}\right)$ or "highway" $\left(100 \mathrm{~km} \mathrm{~h}^{-1}\right)$ a vehicle speed could assigned to the emission factor calculated based on the particulate emission factors. Correspond with David et al. (2008) who studied the particle number emission factors for heavy and light duty vehicles derived from rolling chassis dynamometer and field studies by using New European Driving Cycle (NEDC) the result was similar with Mathis et al. (2004) studied load condition found that the engine operated at low load condition and the particle number rapidly decreased to about $2.0 \times 10^{6} \mathrm{~cm}^{-3}$, even lower than for idling operation, while the particle emission for deceleration operation was mainly composed of nucleation mode particles. The reason could be that more HC and other unburned organic compounds were emitted and were further nucleated to nanoparticles at low engine load condition. Pallavi and Roy M. (2013) studied road traffic was one of the main sources of particulate matter in the atmosphere. Despite its importance, there are significant challenges in quantitative evaluation of its contribution to airborne concentrations. Their studies found that the emission of particulate matter from diesel engine vehicles depend on driving condition. From the study, it was related to the development of air pollutant management from the vehicles by using the correlation of speed and load from diesel engine vehicles affected on the emission of fine particulate matter in Thailand. It was found that the factors of speed and load affect on the emission of fine particulate matter significantly. Moreover, the speed of $7.8 \mathrm{~km} / \mathrm{hr}$ and the load of 0 , 500, and $1,000 \mathrm{~kg}$ also affected on the emission of fine particulate matter most, followed by the speed of $46.8 \mathrm{~km} / \mathrm{hr}$ and $72.6 \mathrm{~km} / \mathrm{hr}$ respectively in the Euro 4 and 3 diesel engine vehicles. Furthermore, it was also found that the Euro 3 diesel engine vehicles have the emission of fine particulate matter two times of the Euro 3 diesel engine vehicles in 3 levels $(7.8,48.6$ and $72.6 \mathrm{~km} / \mathrm{hr})$ which was the representative of driving in the high traffic jam city. It was also found that due to the Euro 3 diesel engine vehicles which were the most of vehicles used in Thailand. The emission factor is defined as the estimated average emission rate for a given pollutant for a given class of vehicles. Emission factors are based on average speed as a mobile source emission inventory for Bangkok was developed for the first time in 1994. The inventory had been improved to encompass the area of Bangkok Metropolitan Region (BMR), which included Bangkok and the five surrounding provinces (Nakhonpathom, Nonthaburi, Pathumthani, Samutprakarn and Samutsakorn). The emission factors for particulate matter in grams per kilometer with vehicles driven at different speeds. Mobile source pollute the air through combustion and fuel evaporation. These emissions contribute greatly to air pollution nationwide and are primary cause of air pollution in many urban areas, on-road motor vehicles are major contributors of emissions of hydrocarbon, carbon monoxide nitrogen oxides, sulfur oxide, particulate matter air toxics and visibility reducing species. Therefore, it should have the policy of urban air quality to control the speed and load of the Euro 4 diesel engine vehicles lower than standard, by using speed should not be less than $7.8 \mathrm{~km} / \mathrm{hr}$ and $1000 \mathrm{~kg}$ for the loads of empty vehicle in the city for reducing the emission of air pollutant; especially the fine particulate matter which can be dangerous to the health of people in the city accordingly. 


\section{Acknowledgements}

We are also in debt to thank the Pollution Control Department for conducting and supporting this study and give special thanks for Department of Environmental Science, Faculty of Environment, Kasetsart University for facilitating and personnel.

\section{References}

Beddows, D. C. S., \& Harrison, R. M. (2008). Comparison of average particle number emission factors for heavy and light duty vehicles derived from rolling chassis dynamometer and field studies. Atmospheric Environment, 42(34), 7954-7966. http://dx.doi.org/10.1016/j.atmosenv.2008.06.021

Corsmeier, U., Imhof, D., Kohler, M., Kuhlwein, J., Kurtenbach, R., Petrea, M., Rosenbohm, E., Vogel, B., \& Vogt, U. (2005). Comparison of measured and model-calculated real-world traffic emissions. Atmospheric Environment, 39(31), 5760-5775. http://dx.doi.org/10.1016/j.atmosenv.2005.06.048

Duangmal, K., Bualert, S., \& Chunkao, K. (2014). Using Multiple-Phase Nozzles to Produce Water Droplets for Removing Smaller Dust Particles of Below MRT-BTS Saphan Khwai Station in Bangkok Thailand. Modern Applied Science, 8(4), 174-186. http://dx.doi.org/ 10.5539/mas.v8n4p174

Khan, Md. F., Shirasuna, Y., Hirano, K., \& Masunaga, S. (2010). Characterization of PM $\mathrm{PM}_{2.5}, \mathrm{PM}_{2.5-10}$ and $\mathrm{PM}_{>10}$ in ambient air, Yokohama, Japan. Atmospheric Research, 96(1), $159-172$. http://dx.doi.org/10.1016/j.atmosres.2009.12.009

Lang, J., Cheng, S., Wei, W., Zhou, Y., Wei, X., \& Chen, D. (2012). A study on the trends of vehicular emissions in the Beijing-Tianjin-Hebei (BTH) region, China. Atmospheric Environment, 62, 605-614. http://dx.doi.org/10.1016/j.atmosenv.2012.09.006

Mathis, U., Kaegi, R., Mohr, M., \& Zenobi, R. (2004). TEM analysis of volatile nanoparticles from particle trap equipped diesel and direct-injection spark-ignition vehicles. Atmospheric Environment, 38(26), 4347-4355. http://dx.doi.org/10.1016/j.atmosenv.2004.04.016

Nilrit, S., Sampanpanish, P., \& Bualert S. (2013). Emission factors of $\mathrm{CH}_{4}$ and $\mathrm{CO}_{2}$ emitted from vehicles. American Journal of Environmental Sciences, 9(1), 38-44. http://dx.doi.org/10.3844/ajessp.2013.38.44

Pant, P., \& Harrison, R. M. (2013). Estimation of the contribution of road traffic emissions to particulate matter concentrations from field measurements: A review. Atmospheric Environment, 77, 78-97. http://dx.doi.org/10.1016/j.atmosenv.2013.04.028

Qi, D. H., Chen, H., Geng, L. M., \& Bian, Y. ZH. (2010). Experimental studies on the combustion characteristics and performance of a direct injection engine fueled with biodiesel/diesel blends. Energy Conversion and Management, 51(12), 2985-2992. http://dx.doi.org/10.1016/j.enconman.2010.06.042

Srimuruganandam, B., \& Shiva Negendra, S. M. (2012). Source characterization of $\mathrm{PM}_{10}$ and $\mathrm{PM}_{2.5}$ mass using a chemical mass balance model at urban roadside. Science of The Total Environment, 433, 8-19. http://dx.doi.org/10.1016/j.scitotenv.2012.05.082

Zhang, Q., Xu, J., Wang, G., Tian, W., \& Jiang, H. (2008) .Vehicle emission inventories projection based on dynamic emission factors: A case study of Hangzhou, China. Atmospheric Environment, 42(20), 4989-5002. http://dx.doi.org/10.1016/j.atmosenv.2008.02.010

\section{Copyrights}

Copyright for this article is retained by the author(s), with first publication rights granted to the journal.

This is an open-access article distributed under the terms and conditions of the Creative Commons Attribution license (http://creativecommons.org/licenses/by/3.0/). 